Arq. Bras. Med. Vet. Zootec., v.67, n.2, p.391-399, 2015

\title{
Diagnóstico etiológico de enfermidades do sistema nervoso central de equinos no Estado de Minas Gerais, Brasil
}

\author{
[Etiologic diagnosis of diseases of the central nervous system of horses \\ in Minas Gerais State, Brazil] \\ E.A. Costa $^{1}$, R. Rosa ${ }^{1}$, T.S. Oliveira ${ }^{2}$, R. Furtini ${ }^{2}$, A.A. Fonseca Júnior ${ }^{3}$, \\ T.A. Paixão ${ }^{4}$, R.L. Santos ${ }^{1 *}$ \\ ${ }^{1}$ Escola de Veterinária - Universidade Federal de Minas Gerais - EV-UFMG - Belo Horizonte, MG \\ ${ }^{2}$ Instituto Mineiro de Agropecuária - IMA - Belo Horizonte, MG \\ ${ }^{3}$ Laboratório de Biologia Molecular - LANAGRO/MG - Pedro Leopoldo, MG \\ ${ }^{4}$ Instituto de Ciências Biológicas - Universidade Federal de Minas Gerais - ICB-UFMG - Belo Horizonte, MG
}

\section{RESUMO}

O Brasil possui o quarto maior rebanho equino do mundo, e o Estado de Minas Gerais detém o maior número de equinos do país. Portanto, um diagnóstico preciso das doenças neurológicas dos equinos é prioridade no estado. Sendo assim, o objetivo deste estudo foi identificar, utilizando a Reação em Cadeia pela Polimerase (PCR), os agentes infecciosos responsáveis por enfermidades que afetam o sistema nervoso central (SNC) de equinos. De janeiro de 2009 a janeiro de 2011, foi realizado um levantamento dos casos de encefalites e encefalomielites em equinos no Estado de Minas Gerais, utilizando-se amostras de SNC de equinos que morreram com sinais neurológicos. Das 217 amostras de SNC, 47 (21,7\%) foram positivas para o vírus da raiva pelo método de imunofluorescência indireta e inoculação em camundongos. Nas 170 amostras negativas para o vírus da raiva, o herpes-vírus equino-1 (EHV-1) foi diagnosticado em 20 (11,8\%) e o herpes-vírus suíno-1 (SHV-1), em uma amostra por meio de PCR, e o vírus encefalite de Saint Louis (SLEV), em outra amostra, através de transcrição reversa (RT) e PCR (RT-PCR). Constatou-se que o vírus da raiva é o principal agente causador de encefalite em equinos, apesar do crescente número de casos de encefalomielite associados ao EHV-1 no Estado de Minas Gerais.

Palavras-chave: cavalo, diagnóstico, encefalite, Brasil

\begin{abstract}
Brazil has the fourth largest equine herd in the world and the State of Minas Gerais has the largest equine population in the country. Therefore, an accurate diagnosis of cases of neurologic diseases is a priority in Minas Gerais. The aim of this study was to identify by Polymerase Chain Reaction (PCR) infectious agents associated with neurological disease in the central nervous system (CNS) of horses. A survey of encephalitis and encephalomyelitis in horses in Minas Gerais State was performed on samples of CNS from horses that died with neurological signs from January 2009 to January 2011. Forty seven CNS samples from 217 (21.7\%) horses were positive for rabies virus by the indirect immunofluorescence assay and mouse inoculation. Among the 170 samples that were negative for rabies, EHV-1 was detected in $20(11.8 \%)$ and the swine herpesvirus-1 (SHV-1) was detected in one sample by PCR, and the Saint Louis encephalitis virus (SLEV) was identified in another sample by reverse transcription (RT) and PCR (RT-PCR). Rabies virus is the most common causative agent of encephalitis in horses, despite the increasing number of cases of encephalitis associated with EHV-1 in the State of Minas Gerais.
\end{abstract}

Keywords: horse, diagnosis, encephalitis, Brazil

Recebido em 15 de abril de 2013

Aceito em 30 de julho de 2014

*Autor para correspondência (corresponding author)

E-mail: rsantos@vet.ufmg.br 


\section{INTRODUÇÃO}

O Brasil possui o quarto maior rebanho equino do mundo, com aproximadamente 5,5 milhões de animais, e o Estado de Minas Gerais detém o maior número de equinos do país (IBGE, 2011). Nesse contexto, para a correta vigilância epidemiológica das doenças neurológicas dos equinos, é necessário o diagnóstico etiológico das encefalopatias que podem afetar essa espécie. Tal diagnóstico é de extrema relevância, uma vez que neuropatias são geralmente fatais e algumas têm potencial zoonótico.

Frequentemente o diagnóstico das doenças neurológicas é realizado apenas pela avaliação dos sinais clínicos. Porém, a confirmação laboratorial da etiologia é importante, uma vez que a sintomatologia nervosa é comum a muitas enfermidades dos herbívoros domésticos (Lima et al., 2005). Em Minas Gerais, o Instituto Mineiro de Agropecuária (IMA) é o órgão responsável pela execução dos programas sanitários do Ministério da Agricultura, Pecuária e Abastecimento (MAPA).

Dentre as enfermidades neurológicas que acometem o SNC dos equídeos, que incluem, além das doenças inflamatórias e infecciosas, doenças metabólicas, nutricionais ou genéticas, traumas, intoxicações, abscessos e neoplasias, neste estudo foram realizados testes diagnósticos para raiva, as infecções por Alfavírus; Flavivírus; Herpes-vírus equino tipo 1 e 4 (Encefalomielite equina); e Herpes-vírus suíno tipo 1 (SHV-1), agente causador da doença de Aujeszky (Summers et al., 1995). No Brasil, apesar de o vírus da raiva ser o principal agente causador de encefalite em equinos, um crescente número de casos de encefalomielite associados ao Herpesvírus equino tipo 1 (EHV-1) tem sido diagnosticado (Costa et al., 2009), inclusive com estudos evidenciando marcadores de neuropatogenicidade em isolados brasileiros (Mori et al., 2011). A mieloencefalite protozoária equina, causada por Sarcocystis neurona, já foi diagnosticada no Brasil (Paixão et al., 2007), mas não foi incluída neste estudo devido à indisponibilidade de amostras de todos os segmentos medulares. Recentemente, Silva et al. (2011) relataram um surto de encefalite equina causada pelo vírus da Encefalite Equina do Leste (EEEV) no nordeste do país. Adicionalmente, evidências sorológicas em equinos indicam a presença dos EEEV, Encefalite Equina do Oeste (WEEV), Encefalite Venezuelana (VEEV) e Encefalite de Saint Louis (SLEV) em locais onde equinos apresentaram doença neurológica seguida de óbito sem diagnóstico conclusivo (Iversson et al., 1993; Pauvolid-Corrêa et al., 2010).

O presente trabalho propõe identificar, através de reação em cadeia da polimerase (PCR) específica, agentes infecciosos causadores de doença neurológica em equinos que tiveram amostras de SNC negativas para raiva, enviadas ao IMA durante o período de janeiro de 2009 a janeiro de 2011. Os agentes infecciosos analisados foram: EHV-1, EHV-4, SHV-1, EEEV, WEEV, VEEV, SLEV e vírus da encefalite equina do Oeste do Nilo (WNEV). Essas informações poderão fornecer subsídios para elaborar futuros programas de controle, avaliar possíveis falhas no uso e a eficiência das vacinas, bem como o acompanhamento de reservatórios naturais.

\section{MATERIAL E MÉTODOS}

Amostras de SNC provenientes de equinos que foram a óbito após sintomatologia neurológica foram coletadas em Minas Gerais por médicos veterinários autônomos e oficiais e encaminhadas ao Laboratório de Saúde Animal do IMA no período de janeiro de 2009 a janeiro de 2011. As amostras foram enviadas refrigeradas (córtex, cerebelo, hipocampo, tálamo e medula) e/ou em formol a $10 \%$ (cérebro, cerebelo, tronco encefálico íntegro e conjunto da rede admirável carotídea, hipófise e gânglios), acompanhadas de um formulário contendo as informações referentes a cada uma, conforme preconizado por Barros e Marques (2003). Os dados obtidos nos formulários referentes às características do animal, como sexo, idade, raça e município de origem, foram catalogados e analisados.

As amostras foram submetidas às análises de imunofluorescência direta (IFD), prova biológica (PB) para o diagnóstico da raiva e histopatologia, dependendo do tipo de conservação de cada uma. Impressões em lâminas das amostras refrigeradas de SNC de equinos foram submetidas à IFD para pesquisa do antígeno da raiva, segundo preconizado por Dean et al. (1996). A PB foi realizada através da inoculação intracerebral (IC) 
de amostras de SNC de equinos em camundongos, como descrito por Koprowski (1996). Foram consideradas positivas para raiva as amostras com resultado positivo em um destes dois testes (IFD ou PB).

Para a avaliação microscópica, amostras de SNC encaminhadas em formol a $10 \%$ foram processadas pela técnica rotineira de inclusão em parafina, submetidas a microtomia seriada e coloração pela técnica da hematoxilina e eosina (HE). As amostras foram previamente seccionadas em segmentos específicos (cérebro, cerebelo, tálamo, gânglio trigeminal, mesencéfalo, ponte, bulbo ou medula), conforme disponibilidade desses segmentos nas amostras.

As amostras negativas para o vírus da raiva foram enviadas ao Laboratório de Patologia Molecular da Escola de Veterinária da UFMG para o diagnóstico através de PCR específicos para EHV-1 e EHV-4 (Varrasso et al., 2001), SHV-1 (Fonseca Jr. et al., 2011) ou RT-PCR para as seguintes arboviroses: SLEV (Ré et al., 2008), WNV, EEEV (Johnson et al., 2003), WEEV e VEEV (Eshoo et al., 2007).

Para a extração do DNA/RNA total, as amostras de fragmentos de SNC (córtex, cerebelo, hipocampo, tálamo e medula) foram suspensas em solução salina tamponada a $20 \%(\mathrm{p} / \mathrm{v})$ e livre de DNA e RNA, homogeneizadas e centrifugadas a $2.000 \mathrm{x} \mathrm{g}$, a $4^{\circ} \mathrm{C}$, por 30 minutos. O sobrenadante foi usado para a extração do DNA total através do protocolo de guanidinasílica, descrito previamente (Boom et al., 1990). O RNA total das amostras de SNC foi extraído segundo método de extração pelo Trizol (Invitrogen Life Technologies, EUA), de acordo com as instruções do fabricante. Foram utilizados 100mg de SNC homogeneizados em $1 \mathrm{~mL}$ de reagente Trizol. As amostras de DNA/RNA total foram quantificadas por espectrofotômetro (Bio-Rad, modelo SmartSpec ${ }^{\mathrm{TM}}$ Plus, EUA).

Para detecção dos EHV-1, EHV-4 e SHV-1, 200ng de DNA total foi utilizada como molde na primeira reação de amplificação contendo $30 \mu \mathrm{L}$ de mix de PCR comercial (Supermix PCR, Invitrogen, Brasil) e $1 \mu \mathrm{M}$ de cada oligonucleotídeo iniciador. Os ensaios de PCR foram feitos em 40 ciclos de desnaturação a $94^{\circ} \mathrm{C}$ por 30 segundos, anelamento a $58^{\circ} \mathrm{C}$
(EHV-1, EHV-1) ou $55^{\circ} \mathrm{C}(\mathrm{SHV}-1)$ por 45 segundos e extensão a $72^{\circ} \mathrm{C}$ por 45 segundos em Termociclador (Mastercycler gradient, Eppendorf, Alemanha). A segunda reação dos semi-nested PCR (EHV-1 e 4) foi feita utilizando-se a mesma concentração dos reagentes da primeira reação e adicionando-se como amplicon, $1 \mu \mathrm{L}$ da primeira reação. Os oligonucleotídeos iniciadores específicos utilizados para detecção dos EHV-1, EHV-4 e SHV-1 foram desenhados e descritos previamente (Varrasso et al., 2001; Fonseca Jr. et al., 2011). Para assegurar a qualidade das amostras de DNA, foi realizada amplificação de parte do gene do fator de crescimento semelhante à insulina 1 (IGF-1), altamente conservado em mamíferos (Mikawa et al., 1995), sob condições previamente descritas (Costa et al., 2009). Os iniciadores utilizados neste estudo estão descritos na Tab. 1.

Para realização do RT-PCR, o cDNA foi obtido a partir do RNA total extraído utilizando-se o kit SuperScriptIII (Invitrogen), conforme instrução do fabricante. As reações de amplificação de parte dos genes estruturais dos WEEV, VEEV (Eshoo et al., 2007), EEEV, WNEV (Johnson et al., 2003) e SLEV (Ré et al., 2008) foram feitas utilizando-se oligonucleotídeo iniciadores específicos previamente descritos para cada tipo viral. A análise dos amplicons foi feita por separação eletroforética em gel de agarose 1,5\%, corados com solução de brometo de etídeo (Invitrogen).

Para confirmar os resultados da técnica de PCR para EHV-1 e SLEV, um amplicon, escolhido aleatoriamente, foi sequenciado no Laboratório de Genética da Escola de Veterinária da UFMG, por eletroforese capilar no aparelho ABI3130, utilizando-se polímero POP7 e BigDye v3.1., Valid Biotechnology. Os fragmentos de DNA amplificados foram sequenciados em ambas as direções da dupla fita, em duplicata, empregando-se os oligonucleotídeos iniciadores senso e antissenso específicos, os mesmos utilizados para PCR. A sequência consenso final obtida de cada amostra foi analisada utilizandose o programa CAP3 Sequence Assembling Program (http://asparagin.cenargen.embrapa.br/ phph), alinhada pelo método do CLUSTAL/W, com o programa BioEdit (1997-2005 versão 5.09 -http://www.mbio.ncsu.edu/BioEdit/bioedit. html) e comparadas com outras sequências 
previamente disponíveis no banco de dados do National Center for Biotechnology Information (NCBI - Bethesda, EUA http://www.ncbi.nlm.nih.gov/) utilizando-se os algoritmos BLASTn (http://www.ncbi.nlm.nih.
gov/BLAST/) do pacote BLAST 2.0 (Basic Alignment Search Tool).

Frequências foram comparadas pelo teste exato de Fisher utilizando-se o GraphPad Instat software.

Tabela 1. Sequência dos oligonucleotídeos iniciadores utilizados neste estudo

\begin{tabular}{|c|c|c|c|c|}
\hline Agente & Sentido & Sequência $\left(5^{\prime} \rightarrow 3^{\prime}\right)$ & $\begin{array}{l}\text { Produto } \\
(\mathrm{pb})\end{array}$ & Referências \\
\hline EHV-1 & $\begin{array}{c}\text { Senso 1 } \\
\text { Antisenso } \\
\text { Antisenso } 2\end{array}$ & $\begin{array}{l}\text { AAGAGGAGCACGTGTTGGAT } \\
\text { TTGAAGGACGAATAGGACGC } \\
\text { AGTAGGTCAGGCCGATGCTT }\end{array}$ & 287 & Varrasso et al., 2001 \\
\hline EHV-4 & $\begin{array}{c}\text { Senso } 1 \\
\text { Antisenso } \\
\text { Antisenso } 2\end{array}$ & $\begin{array}{l}\text { CTGCTGTCATTATGCAGGGA } \\
\text { CGTCTTCTCGAAGACGGGTA } \\
\text { CGCTAGTGTCATCATCGTCG }\end{array}$ & 323 & Varrasso et al., 2001 \\
\hline EEEV & $\begin{array}{c}\text { Senso 1 } \\
\text { Antisenso } 1 \\
\text { Senso } 2 \\
\text { Antisenso } 2\end{array}$ & $\begin{array}{l}\text { AGGGCTTACCTGATTGAC } \\
\text { GTAACGCCAGGAGTATTG } \\
\text { GGCTCAAGAGTCAGGAGA } \\
\text { CGGATGTGACACAAGAGA }\end{array}$ & 140 & Young et al., 2008 \\
\hline VEEV & $\begin{array}{c}\text { Senso } \\
\text { Antisenso }\end{array}$ & $\begin{array}{l}\text { TGCTAATGCCAGAGCGTTTTCGCA } \\
\text { GGGCGCACTTCCAATGTCAAGGAT }\end{array}$ & 98 & Corrêa et al., 2010 \\
\hline WEEV & $\begin{array}{c}\text { Senso } \\
\text { Antisenso }\end{array}$ & $\begin{array}{l}\text { TGCCAATGCCAGAGCGTTTTCG } \\
\text { GGGCGCACTTCCAATGTCCA }\end{array}$ & 98 & Corrêa et al., 2010 \\
\hline SLEV & $\begin{array}{c}\text { Senso } 1 \\
\text { Antisenso } 1 \\
\text { Senso } 2 \\
\text { Antisenso } 2\end{array}$ & $\begin{array}{c}\text { RRYATGGGYGAGTATGGRACAG } \\
\text { CTCCTCCACAYTTYARTTCACG } \\
\text { TGGAYTGGACRCCGGTTGGAAG } \\
\text { CCAATRGATCCRAARTCCCACG }\end{array}$ & 234 & Bronzoni et al., 2005 \\
\hline WNV & $\begin{array}{c}\text { Senso } 1 \\
\text { Antisenso } 1 \\
\text { Senso } 2 \\
\text { Antisenso } 2\end{array}$ & $\begin{array}{c}\text { ACCAACTACTGTGGAGTC } \\
\text { TTCCATCTTCACTCTACACT } \\
\text { GCCTTCATACACACTAAAG } \\
\text { CCAATGCTATCACAGACT }\end{array}$ & 248 & Kleiboeker et al., 2004 \\
\hline $\begin{array}{l}\text { IGF-1 } \\
\text { (controle) }\end{array}$ & $\begin{array}{l}\text { Senso } \\
\text { Antisenso }\end{array}$ & $\begin{array}{c}\text { CTCACTGTCACTGCTAAA } \\
\text { AAGAAATCACAAAAGCAGC }\end{array}$ & 225 & Mikawa et al., 1995 \\
\hline
\end{tabular}

*EHV-1: herpes-vírus equino 1; EHV-4: herpes-vírus equino 4; Sarcocystis neurona, EEEV: vírus da encefalite equina do leste; VEEV: vírus da encefalite equina venezuelana; WEEV: vírus da encefalite equina do oeste; SLEV: vírus da encefalite de Saint Louis; WNV: West Nile vírus; IGF-1: fator de crescimento semelhante à insulina 1.

\section{RESULTADOS E DISCUSSÃO}

As amostras de SNC avaliadas foram obtidas de equinos provenientes de 98 municípios, pertencentes a 45 microrregiões, abrangendo todas as 12 mesorregiões administrativas de Minas Gerais. Dentre as 217 amostras de SNC de equinos examinadas, durante o período de janeiro de 2009 a janeiro de 2011, 47 (21,7\%) foram positivas para o vírus da raiva por meio das técnicas de IFD e/ou PB. A presença do vírus rábico foi detectada em amostras de equinos provenientes de 32 municípios distribuídos em 10 mesorregiões do Estado (Fig. 1). Durante o período avaliado, a infecção pelo vírus da raiva foi diagnosticada somente em casos isolados, caracterizando a ausência de surtos epizoóticos. 


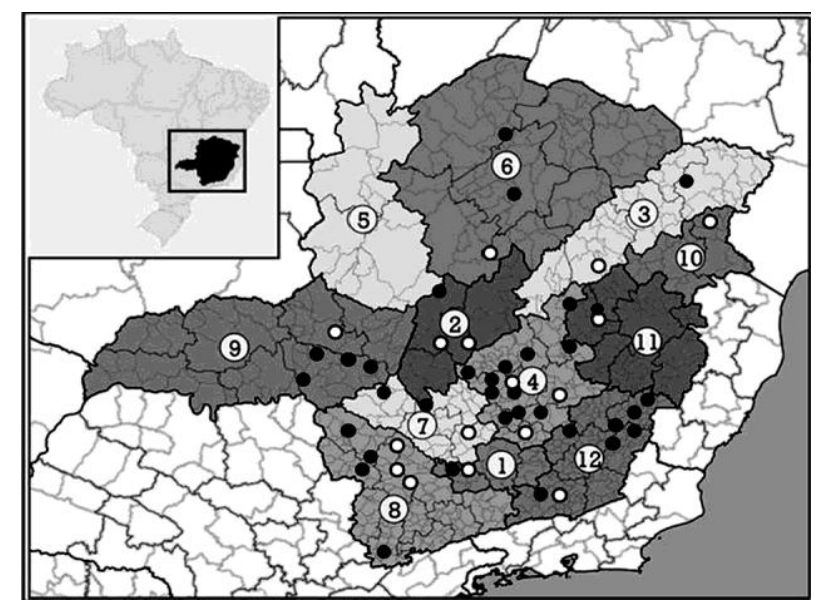

Figura 1. Mapa com distribuição das amostras positivas para o vírus da raiva (círculo cheio) e EHV-1 (círculo vazio) no Estado de Minas Gerais. A presença do vírus rábico foi detectada em 32 municípios e o EHV-1, em 16 municípios amplamente, distribuídos em 10 e 11 mesorregiões do estado, respectivamente. Mesorregiões: 1 - Campo das Vertentes; 2 - Central Mineira; 3 - Jequitinhonha; 4 - Metropolitana de Belo Horizonte; 5 - Noroeste de Minas; 6 - Norte de Minas; 7 - Oeste de Minas; 8- Sul e Sudoeste de Minas; 9 - Triângulo Mineiro e Alto Paranaíba; 10 - Vale do Mucuri; 11 - Vale do Rio Doce; 12 - Zona da Mata.

A dispersão dos casos positivos ocorreu ao longo de todos os meses do ano. No entanto, maior incidência de raiva foi observada entre os meses de março a agosto, indicando tendência sazonal com maior número de casos ao final do período chuvoso e início do período seco. Essa observação pode estar associada à influência tanto das condições climáticas quanto da disponibilidade de abrigos adequados e de alimento aos morcegos transmissores da raiva. São fatores que, em conjunto, podem interferir no deslocamento desses animais, determinando a concentração de populações em áreas mais favoráveis, levando a ocupação de refúgios situados nos vales, nas proximidades da água (Menezes et al., 2008).
Equinos de ambos os sexos, entre várias faixas etárias e raças, foram acometidos pelo vírus rábico. Não houve diferença significativa nas frequências de sexo e faixa etária na comparação entre animais positivos e negativos para raiva (Tab. 1). Foi observada maior frequência da infecção em animais de raça indefinida, com um risco relativo de 1,71 maior que animais de raça pura $(\mathrm{P}<0,05)$ (Tab. 2), com odds ratio de 1,99 . Contudo, tendo em vista a ausência de evidências de predisposição racial para raiva na literatura, a hipótese é de que esse indício não necessariamente reflete uma predisposição racial, mas possivelmente seja decorrente das condições de manejo desses animais, que tendem a diferir entre animais de raça pura e animais de raça indefinida.

Tabela 2. Distribuição de equinos positivos e negativos para raiva, de acordo com sexo, idade e raça

\begin{tabular}{|c|c|c|c|c|}
\hline \multicolumn{2}{|c|}{$\begin{array}{c}\text { Características } \\
\text { avaliadas }\end{array}$} & $\begin{array}{c}\text { Equinos positivos para } \\
\text { raiva }(n=47)\end{array}$ & $\begin{array}{l}\text { Equinos negativos para } \\
\text { raiva }(\mathrm{n}=170)\end{array}$ & $\mathrm{P}$ valor \\
\hline \multirow[t]{2}{*}{ Sexo } & Fêmea & $20(42,6 \%)^{\mathrm{A}}$ & $74(43,5 \%)$ & \multirow[b]{2}{*}{1,00} \\
\hline & Macho & $27(57,4 \%)^{\mathrm{A}}$ & $96(56,5 \%)$ & \\
\hline \multirow[t]{3}{*}{ Idade (anos) } & $\leq 4$ & $26(55,3 \%)^{\mathrm{A}}$ & $87(51,2 \%)$ & \multirow{3}{*}{$\begin{array}{l}0,47 \\
0,24\end{array}$} \\
\hline & 5 a 10 & $15(31,9 \%)^{\mathrm{A}}$ & $67(39,4 \%)$ & \\
\hline & $>11$ & $7(14,8 \%)^{\mathrm{A}}$ & $16(9,4 \%)$ & \\
\hline \multirow[t]{2}{*}{ Raça } & SRD & $29(61,7 \%)^{\mathrm{B}}$ & $76(44,7 \%)$ & \multirow{2}{*}{0,047} \\
\hline & Raça Pura & $18(38,3 \%)^{\mathrm{A}}$ & $94(55,3 \%)$ & \\
\hline
\end{tabular}

FT - Teste Exato de Fisher. *Valores da mesma coluna seguidos de letras diferentes apresentam diferença estatística significativa no Teste Exato de Fisher $(\mathrm{P}<0,05)$. 
Dentre as amostras positivas para raiva, foram selecionadas, de modo aleatório, nove para serem avaliadas histologicamente. Inflamação não supurada foi observada em cinco amostras (55,5\%), caracterizadas por manguitos perivasculares compostos por infiltrado inflamatório linfo-histioplasmocitário, predominantemente nas regiões do córtex cerebral, mesencéfalo e tronco encefálico e meninges, associado à gliose focal. Corpúsculos de inclusão viral, intracitoplasmáticos, redondos a ovais e eosinofílicos (corpúsculos de Negri), foram visualizados em duas das amostras.

Embora o achado de corpúsculos de Negri seja considerado conclusivo para raiva, foi observado somente em duas das nove amostras avaliadas. Peixoto et al. (2000) demonstraram que o corpúsculo de Negri é mais comumente observado no SNC de bovinos infectados com vírus da raiva, em torno de $80 \%$ dos casos, ao passo que, em equinos, observa-se corpúsculo em apenas $36 \%$ dos casos. Esse fato pode ser explicado pela progressão rápida do curso clínico da doença em equinos, de 7 a 10 dias, podendo levar à morte em apenas 3 a 4 dias (Summers et al., 1995). Consequentemente, em geral não há tempo suficiente para o desenvolvimento de alterações histopatológicas características, sendo comum a ausência de lesões no SNC de equinos positivos para raiva. Portanto, faz-se necessário o emprego de técnicas, como IFD, PB como inoculação de camundongos, ou imunohistoquímica, para confirmação da doença.

Dentre as 170 amostras de SNC negativas para o vírus da raiva, provenientes de 82 municípios abrangendo todas as 12 mesorregiões de Minas Gerais, $20(11,8 \%)$ foram positivas para EHV-1 através da técnica de semi-nested PCR (Varrasso et al., 2001). Não houve detecção do EHV-4 no DNA oriundo do SNC de nenhum dos equinos analisados, o que indica baixa frequência desse vírus no Estado de Minas Gerais, uma vez que a metodologia empregada apresenta elevada sensibilidade e especificidade (Varrasso et al. 2001).

As 20 amostras positivas para EHV-1 eram provenientes de 16 municípios, distribuídos em 11 mesorregiões do estado (Fig. 1). A mesorregião com o maior número de casos positivos foi a Metropolitana de Belo Horizonte, com sete casos em 62 submissões. Os casos de
EHV-1 ocorreram durante todos os meses do ano sem nenhum agrupamento sazonal, sendo diagnosticados somente casos isolados, com no máximo dois equinos acometidos por propriedade.

Os sinais nervosos mais relatados nos equinos infectados pelo EHV-1 foram paralisia flácida dos membros pélvicos, incoordenação e ataxia. A paralisia flácida dos membros pélvicos, observada em $76 \% \quad(14 / 20)$ dos animais positivos para EHV-1, foi considerada o único sinal clínico significativamente mais frequente que nos demais animais afetados por doença neurológica $(39 / 150 ; 26 \%$ ) ( $p=0,002)$. Contudo, é importante ressaltar que a avaliação clínica no presente estudo foi realizada por diversos veterinários em condições de campo (veterinários do serviço de vigilância sanitária oficial e autônomos). Portanto, nessas condições de análise de material de campo, os parâmetros de avaliação neurológica não foram padronizados, o que pode ter influenciado a interpretação das alterações clínicas. Geralmente, em equinos, a paralisia flácida dos membros está associada a casos de botulismo (Galey, 2001) ou raiva (Green, 1993), e há relatos em casos de mieloencefalite protozoária equina (Fenger et al., 1997), encefalite equina do Oeste do Nilo (Hayes et al., 2005).

A evolução do curso clínico da encefalite pelo EHV-1 variou de um a nove dias, sendo $75 \%$ dos casos entre um a cinco dias. Equinos de ambos os sexos, de várias raças, vacinados ou não, foram acometidos pelo EHV-1. A idade dos equinos EHV-1 positivos variou de dois dias a 13 anos, sendo $70 \%$ dos casos diagnosticados até quatro anos de idade. Em relação a sexo, fêmeas foram mais frequentemente acometidas pelo EHV-1 neste estudo do que machos $(p=0,01)$ (Tab. 3). Uma provável explicação para essa observação seria a associação dos sinais neurológicos com casos de abortos, uma vez que surtos neurológicos pelo EHV-1 estão frequentemente relacionados a abortos (Dinter e Klingeborn, 1976), contudo essa associação não foi pesquisada no presente trabalho. Casos de doença neurológica por EHV-1 também têm sido relatados em éguas gestantes ou após 30 dias de gestação (Costa et al., 2009). Animais de raça indefinida corresponderam a $65 \%$ dos animais EHV-1 positivos, porém não houve diferença significativa em comparação ao grupo de animais 
de raça pura (Tab. 3). Cabe ressaltar que são reconhecidas três cepas do vírus: HVB-1.1 e HVB-1.2b (pouco prevalente no Brasil), que causam predominantemente inflamação do trato respiratório superior (rinotraqueíte), sendo o
HVB-1.1 também causa de aborto em bovinos. Já o HVB-1.2a está associado predominantemente com vulvovaginite pustular e aborto (Spilki et al., 2004).

Tabela 3. Distribuição de equinos positivos ou negativos para EHV-1, de acordo com sexo, idade e raça

\begin{tabular}{ccccc}
\hline \multicolumn{2}{c}{$\begin{array}{c}\text { Características } \\
\text { avaliadas }\end{array}$} & $\begin{array}{c}\text { Equinos EHV-1 } \\
\text { Positivos (n=20) }\end{array}$ & $\begin{array}{c}\text { Equinos EHV-1 } \\
\text { Negativos (n=150) }\end{array}$ & P valor \\
\hline Sexo & Fêmea & $14(70 \%) \mathrm{B}$ & $60(40 \%)$ & 0,01 \\
& Macho & $6(30 \%) \mathrm{A}$ & $90(60 \%)$ & 0,13 \\
Idade (anos) & $\leq 4$ & $14(70 \%) \mathrm{A}$ & $73(48,7 \%)$ & 1,00 \\
& $5 \mathrm{a} 10$ & $5(25 \%) \mathrm{A}$ & $62(41,3 \%)$ & 0,059 \\
\multirow{2}{*}{ Raça } & $>11$ & $1(5 \%) \mathrm{A}$ & $15(10 \%)$ & \\
& SRD & $13(65 \%) \mathrm{A}$ & $63(42 \%)$ & $87(58 \%)$ \\
\hline
\end{tabular}

FT - Teste Exato de Fisher. *Valores da mesma coluna seguidos de letras diferentes apresentam diferença estatística significativa no Teste Exato de Fisher $(\mathrm{P}<0,05)$.

O produto de PCR de EHV-1 que foi sequenciado teve a sequência depositada no GenBank (www.ncbi.nlm.nih.gov/Genbank) e recebeu o seguinte número de acesso: JN252406. Através da comparação com sequências de nucleotídeos e aminoácidos de amostras de EHV-1, previamente depositadas no GenBank, foi observado um grau de identidade de $99 \%$ com as amostras de referência de EHV-1, V592 (GenBank AY464052) e Ab4 (GenBank AY665713). Embora a genotipagem dos isolados não estejam no escopo do presente estudo, recentemente demonstraram-se marcadores genéticos de neuropatogenicidade em isolados brasileiros de EHV-1 (Mori et al., 2011).

Das 20 amostras de SNC positivas para EHV-1, somente oito foram enviadas ao IMA e fixadas em formol a $10 \%$ para avaliação histopatológica. Em quatro amostras (50\%), foram observadas alterações circulatórias, como hiperemia e hemorragias multifocais no cérebro, tendo sido observada trombose em uma amostra (Tab. 4). Meningoencefalite não supurada multifocal ou difusa, caracterizada por manguitos perivasculares compostos predominantemente por linfócitos e histiócitos localizados no espaço de Virchow-Robin e gliose multifocal, foi observada em dois animais $(25 \%)$. As alterações foram observadas principalmente no cérebro, cerebelo, tálamo e mesencéfalo (Fig. 2). Não foi observada vasculite necrotizante característica dos EHV-1 no encéfalo dos equinos analisados. Geralmente, essas alterações lesões vasculares são observadas com mais frequência na medula espinhal (Henninger et al., 2007).

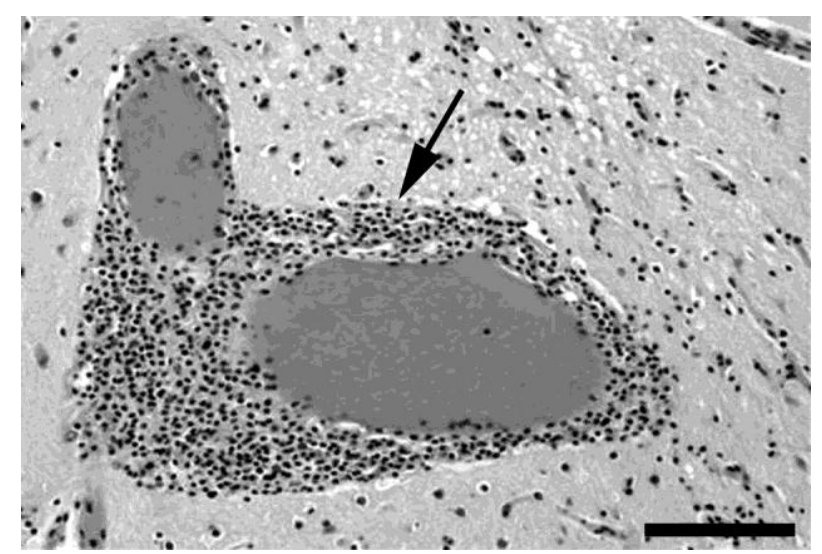

Figura 2. Bulbo de uma égua positiva para EHV-1 através da técnica de PCR. Manguito perivascular linfo-histiocitário associado a hiperemia acentuada (seta); HE, barra $=200 \mu \mathrm{m}$. 
Dentre as 170 amostras de SNC de equinos testadas, somente uma amostra foi positiva para o SVH-1, agente da doença de Aujeszky, por PCR, que amplifica um fragmento específico de 499 pb de parte do gene da glycoprotein $E$ (Fonseca Jr. et al., 2011). Essa amostra não foi enviada em formol, não sendo possível avaliação histopatológica. Os suínos são considerados os reservatórios naturais do SHV-1 e, portanto, responsáveis pela manutenção da doença. Apesar de o SHV-1 infectar várias espécies de mamíferos selvagens e domésticos, os equinos e as aves são considerados pouco susceptíveis à infecção (Pomeranz et al., 2005). Contudo, Kimman et al. (1991) isolaram o vírus da doença de Aujeszky a partir do cérebro de um cavalo que tinha demonstrado sinais neurológicos graves e meningoencefalite não-supurativa na avaliação microscópica. Nossos resultados corroboram a ideia de que SHV-1 deve ser incluído no diagnóstico diferencial de cavalos com neuropatias em áreas onde o vírus é endêmico.

Uma amostra foi positiva para o vírus de Saint Louis (SLEV) através da técnica de transcrição reversa seguida de nested PCR (RT-PCR). Um fragmento específico de 256pb para o SLEV foi detectado utilizando-se iniciadores que amplificam parte do gene da poliproteína do SLEV (Ré et al., 2008). Considerando que esse foi o primeiro diagnóstico da infecção pelo SLEV em um equino no Brasil, tal diagnóstico resultou no desenvolvimento de um modelo de infecção em camundongos neonatos, tendo sido descrito detalhadamente em publicação prévia (Rosa et al., submetido para publicação). Não houve detecção das outras arboviroses testadas (WNV, EEEV, WEEV, VEEV) no SNC dos equinos analisados.

\section{CONCLUSÃO}

Neste estudo, foi constatada prevalência mais elevada do vírus da raiva $(21,7 \%)$ dentre os agentes causadores de doença neurológica no SNC de equinos. A pesquisa por outros agentes virais nas amostras que foram negativas para 0 vírus da raiva revelou a presença do EHV-1 em $11,8 \%$ das amostras, além de um caso de infecção pelo SVH-1, agente da doença de Aujeszky, e um caso de infecção pelo SLEV.

\section{AGRADECIMENTOS}

Este trabalho teve o apoio financeiro do Conselho Nacional de Desenvolvimento Científico e Tecnológico (CNPq), projeto 578385/2008-2, e parceria dos órgãos de Defesa Animal Federal e Estadual: Ministério da Agricultura, Pecuária e Abastecimento (MAPA) e Instituto Mineiro de Agropecuária (IMA), respectivamente.

\section{REFERÊNCIAS}

BARROS, C.S.L.; MARQUES, G.H.F. (ed). Procedimentos para o Diagnóstico das Doenças do Sistema Nervoso Central de Bovinos. Brasília: Depto Defesa Animal, Ministério da Agricultura, Pecuária e Abastecimento (MAPA), 2003. 50p.

BOOM, R.; SOL, C.J.; SALIMANS, M.M. et al. Rapid and simple method for purification of nucleic acids. J. Clin. Microbiol., v.28, p.495-503, 1990.

COSTA, E.A.; VASCONCELOS, A.C.; BOMFIM, M.R.Q. et al. Epidemiological and clinical aspects of equine Herpesvirus encephalitis infection in horses that died with neurological signs from Minas Gerais state, Brazil. Braz. J. Vet. Res. Anim. Sci., v.46, p.262272, 2009.

DEAN, D.J.; ABELSETH, M.K.; ATANASIU, P. The fluorescent antibody test In: MESLIN, F.X.; KAPLAN, M.M.; KOPROWSKI, H. (ed). Laboratory techniques in rabies. Geneve: World Health Organization, 1996. p.88-95.

DINTER, Z.; KLINGEBORN, B. Serological study of an outbreak of paresis due to equid herpesvirus 1 (EHV-1). Vet. Rec., v.99, p.10-12, 1976.

ESHOO, M.W.; WHITEHOUSE, C.A.; ZOLL, S.T. et al. Direct broad-range detection of alphaviruses in mosquito extracts. Virology, v.368, p.286-295, 2007.

FENGER, C.K.; GRANSTROM D.E.; GAJADHAR, A.A., et al. Experimental induction of equine protozoal myeloencephalitis in horses using Sarcocystis sp. sporocysts from the opossum (Didelphis virginiana). Vet. Parasitol., v.68, p.199213, 1997.

FONSECA Jr., A.A.; COSTA, E.A.; OLIVEIRA, T.S. et al. Multiplex PCR for detection of Suine herpesvirus 1, Bovine herpesvirus 1, Bovine herpesvirus 5, Ovine herpesvirus 2. Arq. Bras. Med. Vet. Zootec., v.63, p.1405-1413, 2011.

GALEY, F.D. Botulism in the horse. Vet. Clin. North. Am. Equine, v.17, p.579-588, 2001.

GREEN, S.L. Equine rabies. Vet. Clin. North. Am. Equine, v.9, p.337-347, 1993. 
HAYES, E.B.; SEJVAR, J.J.; ZAKI, S.R. et al. Virology, pathology, and clinical manifestations of West Nile virus disease. Emerg. Infect. Dis., v.11, p.1174-1179, 2005.

HENNINGER, R.W.; REED, S.M.; SAVILLE, W.J. et al. Outbreak of neurologic disease caused by equine herpesvirus-1 at a university equestrian center. J. Vet. Intern. Med., v.21, p.157-65, 2007.

IBGE. Produção da pecuária municipal, v.39, p.1-60, 2011.

IVERSSON, L.B.; SILVA, R.; DA ROSA, A. et al. Circulation of Eastern equine encephalitis, Western equine encephalitis, Ilhéus, Maguari and Tacaiuma viruses in equines of the Brazilian Pantanal, South America. Rev. Inst. Med. Trop., v.35, p.355-359, 1993.

JOHNSON, D.J.; OSTLUND, E.N.; PEDERSEN, D.D.; SCHMITT, B.J. Detection of North American West Nile virus by a reverse transcription nested polymerase chain reaction. Emerg. Infect. Dis., v.4, p.739-741, 2003.

KIMMAN, T.G.; BINKHORST, G.J.; VAN DEN INGH, T.S. et al. Aujeszky's disease in horses fulfils Koch's postulates. Vet. Rec., v.128, p.103-106, 1991.

KOPROWISKI, H. The mouse inoculation test. In: MESLIN, F.X.; KAPLAN, M.M.; KOPROWSKI, H. (ed) Laboratory Techniques in rabies. Geneve: World Health Organization, 1996. p.88-96.

LIMA, E.F.; RIET-CORREA, F.; CASTRO, R.S. et al. Sinais clínicos, distribuição das lesões no sistema nervoso e epidemiologia da raiva em herbívoros na região Nordeste do Brasil. Pesq. Vet. Bras., v.25, p.250-264, 2005.

MENEZES, F.L.; SILVA, J.A.; MOREIRA, E.C. et al. Distribuição espaço-temporal da raiva bovina em Minas Gerais. Arq. Bras. Med. Vet. Zootec., v.60, p.566-573, 2008.

MIKAWA, S.; YOSHIKAWA, G.; AOKI, H. et al. Dynamic aspects in the expression of the goat insulinlike growth factor-1 (IGF-1) gene: diversity in transcription and post-transcription. Biosci. Biotechnol. Biochem., v.59, p.87-92, 1995.
MORI, E.; BORGES, A.S; DELFIOL, D.J, et al. First detection of the equine herpesvirus 1 neuropathogenic variant in Brazil. Rev. Sci. Tech., v.30, p.949-954, 2011.

PAIXÃO, T.A.; REGO, I.O.P.; SANTOS, R.L. AntiSarcocystis neurona immunostaining associated with equine protozoal myeloencephalitis in Brazil. Cienc. Rural, v.37, p.1820-1823, 2007.

PAUVOLID-CORREAA, A.; TAVARES, F.N.; COSTA, V.E. et al. Serologic evidence of the recent circulation of Saint Louis encephalitis virus and high prevalence of equine encephalitis viruses in horses in the Nhecolândia subregion in South Pantanal, centralWest Brazil. Mem. Inst. Oswaldo Cruz, v.105, p.829833, 2010 .

PEIXOTO, Z.M.P.; CUNHA, E.M.S.; SACRAMENTO, D.R.V. et al. Rabies laboratory diagnosis: peculiar features of samples from equine origin. Braz. J. Microbiol., v.31, p.72-75, 2000.

POMERANZ, L.E.; REYNOLDS, A.E.; HENGARTNER, C.J. Molecular biology of pseudorabies virus: impact on neurovirology and veterinary medicine. Microbiol. Mol. Biol. Rev., v.69, p.462-500, 2005.

RÉ, V.; SPINSANTI, L.; FARÍAS, A. et al. Reliable detection of Saint Louis encephalitis virus by RTnested PCR. Enferm. Infecc. Microbiol. Clin., v.26, p.10-15, 2008.

SILVA, M.L.; GALIZA, G.J.; DANTAS A.F. et al. Outbreaks of Eastern equine encephalitis in northeastern Brazil. J. Vet. Diagn. Invest., v.23, p.570$575,2011$.

SPILKI, F.R.; ESTEVES, P.A.; LIMA, M. et al. Comparative pathogenicity of bovine herpesvirus 1 (BHV-1) subtypes 1 (BHV-1.1) and 2a (BHV-1.2a). Pesq. Vet. Bras., v.24, p.43-49, 2004.

SUMMERS, B.A.; CUMMINGS, J.F.; DE LAHUNTA, A. (ed). Veterinary Neuropathology. St. Louis: Mosby-Year Book, 1995. 527p.

VARRASSO, A.; DYNON, K.; FICORILLI, N. et al. Identification of equine herpesviruses 1 and 4 by polymerase chain reaction. Aust. Vet. J., v.79, p.563$569,2001$. 